\title{
Cartografando intercâmbios de saberes com grupos artesanais da Baixada Maranhense e Alcântara
}

\author{
Mapping knowledge exchanges with artisanal groups \\ from the Maranhense Lowlands and Alcântara
}

\author{
NORONHA, Raquel; Doutora; Universidade Federal do Maranhão \\ raquelnoronha79@gmail.com \\ CAMPOS, Alice; Graduando; Universidade Federal do Maranhão \\ alicecamposs@outlook.com \\ CAMARA, Larissa; Graduando; Universidade Federal do Maranhão \\ camaralarissa@outlook.com
}

\section{Resumo}

O estudo aborda o processo de construção do pensamento projetual, de forma empírica, entre artesãos e artesãs de Alcântara e da Baixada Maranhense (MA). A partir da prática do intercâmbio como etapa do percurso metodológico, entre os grupos produtivos, é possível analisar características específicas de cada artesão durante a troca de conhecimentos. As reflexões teóricas e metodológicas adotadas no desenvolvimento do projeto têm como fundamento o codesign, filosofia de projeto na qual o designer atua como mediador e facilitador de processos em seu campo de pesquisa. Portanto, a partir do método, busca-se a necessidade de percorrer um caminho, sem metas definidas a priori e, desta forma, o campo e os sujeitos da pesquisa nos mostram a direção a seguir. Desta forma, possibilita reflexões sobre a prática cartográfica, gerado por discursos e práticas sobre o saber-fazer em comunidades artesãs, no campo do design. Assim, como resultado, cartografias foram criadas como produto da sistematização dos saberes e fazeres durante o percurso de pesquisa.

Palavras Chave: cartografia; codesign; saberes tradicionais.

\section{Abstract}

The study deals with the process of construction of the project thought, in an empirical way, between artisans of Alcântara and of the Maranhense Lowlands (MA). Taking the practice of the exchange as a step of the methodological course, among the productive groups, it is possible to analyze specific characteristics of each artisan during the exchange of knowledge. The theoretical and methodological reflections adopted in the project development are based on the codesign, a project philosophy in which the designer acts as mediator and facilitator of processes in his field of research. Therefore, from the method, one searches for the need to follow a path, without goals defined a priori and, in this way, the field and the subjects of the research show us the direction to follow. In this way, it allows reflections on the mapping practice, generated by discourses and practices on the know-how in artisan communities, in the field of design. Thus, as a result, mapping were created as a product of the systematization of knowledge and actions during the course of research.

Keywords: mapping; codesign; traditional knowledge. 


\section{Introdução}

Metodologias colaborativas permitem o acolhimento dos saberes não especializados como base para o projeto de design. A própria noção de projeto pode ser problematizada, se tomar como ponto de partida para o projeto, o ponto de vista daqueles que não possuem formação especializada em design, aqueles que Manzini nomeia por designers difusos (Manzini, 2015, p.37). Ao longo do tempo, a presença de atores sociais diversificados nas instâncias projetuais trazem novas ideias sobre o próprio fazer do designer. Pensando em experiências de codesign nos contextos socioculturais, o autor diz que o papel dos designers vem mudando, deslocando-se da atividade de finalizador de processos e produtos para a de mediador de processos e tangibilizador de artefatos de mediação e facilitação.

Segundo Thackara, "nessa nova era de inovação colaborativa, os designers estão tendo de evoluir de autores individuais de objetos, ou construções, a facilitadores da mudança entre grandes grupos de pessoas" (THACKARA, 2008, p. 21). A partir dessa maneira de se pensar o processo projetual, busca-se neste artigo observar os discursos e as práticas apreendidos em campo durante o mapeamento de cadeias produtivas de artesanato $^{1}$ em Alcântara e na Baixada Maranhense e como tais atores sociais refletem sobre seus processos produtivos, tangenciando noções referentes ao processo de design como criatividade, imaginação e projeto propriamente dito. Para isso, far-se-á o uso da reflexão sobre design como um processo complexo. Como observa Rafael Cardoso, "as aparências características dos objetos nos remetem a vivências, hábitos e até pessoas que estavam associadas ao contexto que conviviam, acostumados a nos deparar com eles. Mais uma vez, o mecanismo prioritário de identificação do sentido é a memória" (CARDOSO, 2008, p.110).

Dessa forma, identificou-se as categorias analíticas projeto e criatividade como elementos principais acionados pelos designers difusos. De acordo com os estudos do antropólogo Tim Ingold (2010) sobre criatividade e imaginação, não é somente o ato de formar no imaginário imagens de outra realidade e da realidade que se conhece mas, principalmente, um jeito de viver de forma criativa em um mundo em crescente expansão, em um processo de correspondência (INGOLD, 2011; 2018) que irá nortear nossas reflexões sobre a fala dos artesãos e sobre seus processos produtivos.

\section{Percurso metodológico}

O designer assume o papel de mediador no campo da pesquisa, no qual pode intervir de maneira que possa conciliar a complexidade no processo de aquisição de conhecimento para, consequentemente, compartilhar tal conhecimento, na forma de um artefato ou serviço. No caso aqui apresentado, o conhecimento sobre os saberes e fazeres, a identidade étnica e as relações entre a produção e a natureza são os assuntos abordados nas conversas entre designers e artesãos. Segundo Noronha (2012), o designer vai ao campo para entender as condições culturais, econômicas e sociais antes de projetar e dedica-se a entender as condições de uso do artefato que será projetado e, ainda, pode avaliar a conveniência de sua inserção em determinado contexto.

\footnotetext{
${ }^{1}$ Serão apresentados neste artigo resultados do projeto "Intercâmbio de estratégias vernaculares de produção, promoção e comercialização do artesanato entre grupos de Alcântara e Baixada Maranhense", financiado pelo edital Tecnologias Sociais da FAPEMA, e do projeto de extensão "Iconografias do Maranhão" que pretendem, a partir do intercâmbio, promover o compartilhamento de saberes e fazeres, gerando inovações bottom-up em suas cadeias produtivas de valor.
} 
Por esse motivo, o cerne dos processos projetuais compreende vários novos conceitos e recursos, como o reconhecimento dos diversos atores sociais como codesigners, que participam da prática projetual de forma colaborativa e não somente como informantes da pesquisa que propicia informações ao designer. Esta pesquisa foi realizada seguindo tais conceitos, considerando o designer atuando enquanto mediador de processos culturais.

O percurso metodológico consistiu-se da pesquisa de campo associada ao método cartográfico. Desta forma, acionou-se autores da antropologia, sociologia, psicologia, filosofia, geografia que, juntos, trazem ao campo do design a possibilidade de se valer da cartografia como filosofia de projeto. O percurso foi realizado nas seguintes etapas: survey $>$ intercâmbio entre grupos produtivos $>$ análise de resultados $>$ tangibilização do percurso cartográfico $>$ consolidação de resultados com os grupos.

O processo iniciou-se com visitas iniciais, uma aproximação com as mulheres de Mirinzal, grupo autointitulado de Anas das Louças. São quatro irmãs e uma sobrinha, todas Anas, que fazem panelas de barro e alguidares, utilizando-se da técnica da "queima no tempo" ou seja, queimam suas peças em uma fogueira, sem o uso de forno. O outro grupo com quem a ação foi desenvolvida foram as mulheres de Itamatatiua com quem já se mantinha relações de pesquisa desde 2010. Na ocasião, em Itamatatiua, foi conhecido o artesão Zé Dico, que trabalhou sua vida toda em olarias, e também possui grande intimidade com o barro.

A chegada no novo campo, Porto dos Nascimentos, onde vivem as Anas das Louças, foi intermediada pelo oleiro, que havia morado há alguns anos atrás no povoado. A relação que estabelecemos foi, portanto, a partir da confiança, traço que Sade, Ferraz e Rocha $(2014$, p.69) identificam como a base sobre a qual a cartografia se constitui: "Eis o que encontramos na palavra confiança: con/fiar - fiar com, tecer com, composição e criação com o outro/outrem."

Assim, a cartografia se constitui como a construção de um plano comum (KASTRUP E BARROS, 2014, p.15) em que as ideias, desejos e prerrogativas sobre determinado tema é construído mutuamente. No campo do design, ainda são poucas as iniciativas sobre a cartografia como método (SZANIECKI, 2013; NORONHA et al, 2017); ambas as autoras trabalham com a perspectiva cartográfica em contextos de compartilhamento de ideias e prerrogativas em projetos de design com cunho social, em que os denominados nativos são interlocutores ativos, no que foi visto denominando aqui como codesign. Nas palavras de Manzini,

a comunicação entre os seres humanos envolve o que todo encontro colaborativo propõe, um grau de envolvimento pessoal e empatia. As relações entre seres humanos é um encontro que, por natureza, é envolvente e profundo, sendo muitas vezes catalogado como uma relação complexa, porém precisa, para que processos como amadurecimento e troca de experiências façam parte de um processo de evolução nas relações interpessoais. (MANZINI, 2015, p.103, tradução nossa).

Após o primeiro encontro, o processo de familiarização com os atores sociais ocorreu gradualmente de acordo com as visitas. Nesse segundo momento de encontros, com conversas e debates, foi refletido coletivamente como o design provocaria melhorias e soluções com base no processo produtivo, com a participação e a colaboração de todos, para que peças-chave do estudo fossem descobertas, identificadas e exploradas.

O papel dos designers como mediadores nesta etapa da pesquisa de campo, de cunho etnográfico serve, também, para guiar e auxiliar as conversações. Os designers devem instigar os sujeitos de pesquisa que, muitas vezes, ainda podem estar tímidos, a manter diálogos e indicar 
discretamente caminhos que a conversa deve seguir para obtenção de informações desejadas. Neste tipo de conversas é possível obter as mais diversificadas e importantes informações, pois ao sentir-se mais à vontade, o coautor irá relatar fatos não apenas profissionais, mas de sua vida e, assim, o pesquisador poderá realizar uma análise melhor sobre o contexto. Assim, essa etapa consiste na realização de entrevistas com os artesãos em forma de conversa, geralmente realizadas em grupo durante as atividades de campo ou em seu local de descanso, deixando-as mais à vontade. As perguntas foram feitas de forma livre durante a conversa, seguindo um roteiro simples, sobre o papel do artesão e do artesanato, direcionando as perguntas para se obter as respostas desejadas.

Após este momento de construção de laços de confiança e entendimento dos processos produtivos locais, das histórias de vida e perspectivas de cada ator social, foi realizado o intercâmbio entre os dois grupos de mulheres que têm em comum a produção de cerâmica, produtos como vasos, jarros e panelas, a saber as mulheres de Itamatatiua, do município de Alcântara, e as Anas das Louças, do povoado de Porto dos Nascimentos, no município de Mirinzal. Nas duas ocasiões, nos encontros em cada um dos povoados, foi possível identificar práticas específicas de cada cadeia produtiva, entraves e soluções vernaculares para lidar com eles. A estas práticas nomeou-se tecnologias sociais, que foram entendidas a partir da ideia que são os os próprias artesãs, aquelas que detém o maior conhecimento sobre seus fazeres, em detrimento dos designers experts, para acompanhar a reflexão de Manzini (2015).

A rica experiência da construção da confiança e do plano comum proporcionada pela cartografia, partiu-se para a análise e classificação dos discursos e práticas construídas em campo. As referências foram analisadas a partir das categorias nativas, observadas no próprio campo. Fichas com as falas dos atores sociais foram sendo abertas, as quais foram analisadas a partir da incidência e reincidência dos temas. O conteúdo, portanto, foi direcionado pelo próprio campo, não havendo, de fato, algo definido de forma rigorosa, a priori.

Figura 1 - Classificação das falas transcritas, em categorias analíticas.

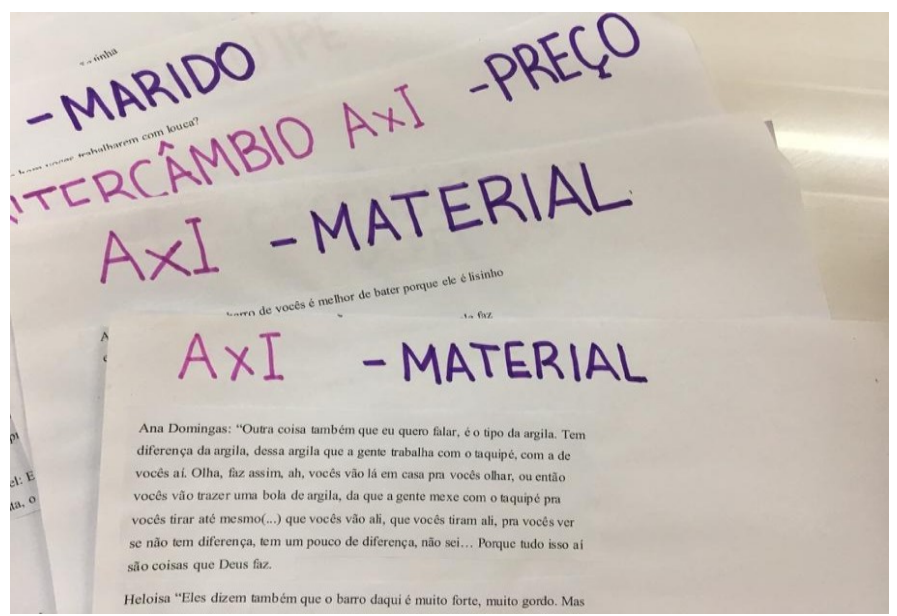

Fonte: Autoras, 2016.

Com os recortes de falas e pensamentos foi possível tangibilizar a complexidade da experiência por meio de cartografias, construídos como conjuntos de mapas que trazem camadas diversas de informação: epistemológicas, discursivas e empíricas, mesclando falas e imagens 
obtidas em campo, assim como as próprias reflexões dos pesquisadores. Para Escóssia e Passos (2013), o plano comum é uma construção transversal, que busca a ruptura com a verticalidade que hierarquiza as diferenças e com a horizontalidade, que as homogeneíza, abrindo o espaço de diálogo e de complexidade, já que não é a igualdade que cria a comunidade, mas a variação, nas palavras de Ingold (2018).

Os usos de imagens, como a fotografia e o vídeo, trazem, ao processo de construção de conhecimento, uma possibilidade de se construir outras formas de saberes, para além da observação direta e das entrevistas. As cartografias surgem como forma de construir e sistematizar a informação obtida em campo, a partir da multiplicidade dos pontos de vistas - dos produtores, dos pesquisadores, dos mediadores, das cadeias produtivas e da louça, em ambas as comunidades.

Enquanto forma visual, a cartografia caracteriza-se por múltiplas camadas de informação, sendo mídia privilegiada para a representação de discursos e práticas. O que foi proposta é a reflexão sobre a eficácia da cartografia como elemento síntese das diversas fases da construção do conhecimento: dados > informação > conhecimento. A proposta de se seguir pistas, como Barros, Kastrup e Escóssia (2015) nos propõem, é uma estratégia que, conceitualmente e na prática, nos coloca o campo de pesquisa e a pesquisa propriamente dita como um espaço a ser explorado, territorializado.

\section{A teoria e a prática}

Os artesãos - considerados coautores desta pesquisa - apesar de terem práticas um tanto diferenciadas entre si, em relação a sua produção e seus produtos, possuem em comum algumas características: o trabalho com o barro; o entendimento da sazonalidade da região da Baixada Maranhense, o que interfere na extração da matéria-prima e na modelagem do barro; o aprendizado empírico, com os antepassados; e a resistência em manter vivo um saber-fazer pouco reconhecido e mal remunerado.

Em ambos os lugares, também podemos observar o domínio de técnicas manuais que caracterizam o trabalho artesanal. Na base conceitual do artesanato brasileiro, construído no âmbito do Programa do Artesanato Brasileiro, entende-se que artesanato:

Compreende toda a produção resultante da transformação de matérias-primas, com predominância manual, por indivíduo que detenha o domínio integral de uma ou mais técnicas, aliando criatividade, habilidade e valor cultural (possui valor simbólico e identidade cultural), podendo no processo de sua atividade ocorrer o auxílio limitado de máquinas, ferramentas, artefatos e utensílios (BRASIL, 2012, p. 12).

É importante ressaltar que os artesanatos abordados neste artigo são tradições passadas de geração em geração, entre familiares e amigos em laços de compadrio e vizinhança. Em pequenas comunidades, $\mathrm{o}$ artesanato assume fonte de renda principal de famílias, principalmente no meio rural, às vezes intercalado com atividades como agricultura ou extrativismo (de onde se tira a matéria-prima para uso pessoal e comercial) de forma que incremente sua renda para o sustento de sua família. Os objetos produzidos para o artesanato são pensados a partir de princípios que são comumente relacionados ao design como, por exemplo, o auxílio sobre a função e utilização de certas matérias-primas e determinadas técnicas sobre o processo produtivo. 
Com a abertura e o compartilhamento das atividades projetuais, em campo, observandose os artesãos na posição de designers, pode-se perceber como a atividade projetual norteia as suas reflexões. Foi possível observar que existe um fio condutor que alia a criatividade e a imaginação, associados à experiência prática de se modelar o barro. Essa associação entre o saber e o fazer - o que é transmitido pela oralidade e reafirmado pela manualidade - é o que caracteriza o conhecimento artesanal. A característica da antecipação do resultado - o foresight, nas palavras de Tim Ingold (2012b, p.6) - este movimento de pensar à frente, que caracteriza a atividade projetual, é o que propicia o processo da imaginação. Quando designers chegam a comunidades, já encontram uma forma de produzir baseada nesta antecipação do resultado, do que é esperado pelo outro. Contudo, para Ingold, essas formas de antever - a do designer e a do artesão diferenciam-se da seguinte maneira:

Este é o trabalho [o do artesão] que exige visão qualificada e destreza manual. Ele também pede antevisão. Mas esta antevisão é de um tipo muito diferente daquilo que se determina como um requisito de design, para um designer. Não está na reflexão que, literalmente, vem antes da vista, mas na própria atividade de ver à frente, não em preconceito, mas no que o sociólogo Richard Sennett, em seu estudo sobre o trabalho do artesão, chama a expectativa: estar sempre com um passo à frente do material '. [...] Esta é uma questão não de predeterminar as formas finais das coisas e todas as etapas necessárias para chegar lá, mas de abrir um caminho e improvisar uma passagem. Prever, neste sentido, é ver no futuro, não projetar um futuro estado de coisas no presente; é olhar para onde você está indo, e não para fixar um ponto final (INGOLD, 2012b, p.6).

Essa abordagem de Ingold ajuda na problematização das metodologias de projeto de design, principalmente as que envolvem comunidades tradicionais. Como mencionado anteriormente, diversas são as críticas sobre as hierarquias entre saberes acadêmicos e os tradicionais, entre elas, principalmente, constam aquelas em que a criatividade do artesão é tolhida pelos direcionamentos estético-formais dos designers. Em conversas realizadas com Zé Dico durante a pesquisa, ele contou sobre seu processo criativo, que associa a prática e a memória:

Eu tenho assim na memória e vivo na prática, né? E vivo na prática de cada dia. Eu vivo na prática até hoje. Eu tenho quarenta e cinco anos e todo tempo trabalhando com o barro. Então você tem aquela prática, né? Tanto aqui na cabeça como tem nas mãos, de fazer com as mãos... Porque às vezes você é uma profissional, mas você não mete a mão lá pra fazer. Você tem o estudo, na mente, na cabeça: ó, faz, assim... mas você não tem aquela habilidade de chegar com a mão e fazer... ${ }^{2}$

O artesão, que aprendera na prática, com o pai, reflete sobre a diferença dos saberes, e a capacidade de colocar em prática tais saberes, por meio da ligação entre a memória e o trabalho prático. O domínio do saber e do fazer, para Zé Dico, o diferenciam e o qualificam, em detrimento de pessoas que detém um saber especializado e não possuem a habilidade.

Noronha $(2011 ; 2012)$ reflete sobre o processo de identificação destes valores em comunidades artesãs do Maranhão e como a auto-observação propicia um estranhamento sobre o próprio conhecimento: ao analisarem e descreverem suas próprias cadeias produtivas, os artesãos

\footnotetext{
${ }^{2}$ Entrevista concedida por Zé Dico à Raquel Noronha, em 05 de dezembro de 2016, em Itamatatiua.
} 
distanciam-se e podem identificar melhor os pontos positivos e negativos dos processos e, assim, junto com os designers experts (Manzini, 2015) podem acionar seu imaginário buscando soluções.

$\mathrm{Na}$ experiência desse projeto, o intercâmbio tido com prática cartográfica, abre portas para a problematização no campo da pesquisa. A reflexividade torna-se ponto chave para se entender o outro. A experiência da alteridade em campo proporciona desenho coletivo e complexo da cartografia, que permite a profusão de vozes coexistindo em uma superfície gráfica. As negociações que se estabelecem no campo são traduzidas para o texto, na forma de polifonia.

E quando se fala em texto, está indo além da palavra escrita. Como conduz o antropólogo James Clifford (2008), o texto é uma textura, fruto de diversas citações, diretas e indiretas, implícitas e explícitas; inclui a forma como foram vistos o mundo e as experiências vivenciadas. Sendo assim, além de um conjunto de palavras escritas - inclui os discursos e práticas de todos os coautores.

\section{As trocas de conhecimento}

Para execução do projeto, foram realizadas visitas aos grupos produtivos para melhor conhecimento e entendimento do campo em pesquisa. Nestes processos de pesquisa e intermediação, pôde-se observar que os atores já possuem conceitos, de forma empírica, sobre desenvolvimento e prática de projeto. Tais conceitos são formulados embasados no que eles vivenciam. Segundo Lemos, o artesanato pode ser entendido como "um complexo de atividades de natureza manual, através das quais o homem manifesta a criatividade espontânea" (LEMOS, 2011, p.14 apud PEREIRA, 1979, p.21). Tal afirmação pode ser confirmada pela fala das Anas sobre processo criativo e de produção:

A minha mãe foi me ensinando como era... Era assim, os potes assim, essa fase de aprendizado da gente vem tudo da mente, do raciocínio da mente. A gente não consegue fazer nada se o raciocínio da mente não funcionar, aí fui aprendendo com ela. ${ }^{3}$

Com esse discurso e observações feitas em campo, pode-se entender que, além dos ensinamentos passados hereditariamente, têm-se as inovações criadas a partir de atos espontâneos que possuem interferência indireta do local de vivência dos produtores. No sistema de produção artesanal, o produto final é influenciado pelo artesão e suas habilidades, métodos e experiências. Como afirmado por Thackara, "qualquer pessoa que utilize um sistema - reagindo a ele, interagindo com ele, alimentando-o com informações - também o está alterando" (THACKARA, 2008, p.269). Isso inclui turistas, visitantes e outros compradores dos produtos.

Observa-se que o processo de construção do imaginário sobre o produto é coletivo e formado por remissões discursivas como nos sugere Michel Foucault (2010). A construção do discurso, para o autor, se dá pela sobreposição de práticas, falas, hábitos e conceitos estabelecidos pela vivência e pela experiência cotidiana, pelas interações com outros atores sociais, e isso inclui os próprios discursos hierárquicos e de poder.

Dessa forma, foi possível refletir sobre as questões observadas em campo. Neste sentido, as artesãs adaptam os seus produtos às necessidades dos consumidores como pode ser analisado na fala de Ana Amélia, a mais idosa artesã de Porto dos Nascimentos, com 84 anos:

\footnotetext{
${ }^{3}$ Entrevista concedida por Ana Domingas em setembro de 2016 a Raquel Noronha.
} 
Eu tenho essas coisas que eu criei, uma travessa... A gente só fazia panela, alguidar e pote, e eu aprendi a fazer travessa, fazer tigelinha, pratos, e já aprendi fazer frigideiras, até joinhas... Se for fazer, eu faço isso aqui. Esses beicinhos aqui todo pisadinho. Agora com essa venda aqui, eu vou um pouco modificar, inclusive, fazer minhas travessas, minhas panelas... Mas vou modificar um pouco, do meu jeito ${ }^{4}$

Portanto, observa-se que os gostos e opiniões dos turistas e consumidores interferem nas definições de projeto dos artesãos. Esta adaptação às necessidades dos consumidores é uma abordagem pertinente a ambos universos criativos - do design e do artesanato - e atender os desejos e as necessidades de seu público. Deve-se enfatizar que o designer realiza esse objetivo baseado em metodologias científicas e pesquisas, enquanto o artesão, como já dito, faz isso espontaneamente, por meio do conhecimento prático, adquirido na relação com o material, na antecipação do seu uso, como foi refletido a partir de Ingold (2012).

Durante a troca de conhecimento realizada no intercâmbio, foi mapeado durante essa etapa do processo produtivo, a partir de dados qualitativos, que o uso específico da casca de uma árvore, chamada taquipé, adicionada ao barro, permite à louça produzida com essa mistura ir à queima em alta temperatura, proporcionando a cerâmica dessa comunidade, alta durabilidade e resistência, além de outras especificidades, a exemplo do uso da resina do jatobá, denominada jutaicica, que garante impermeabilização e brilho no acabamento na peça final.

Enquanto na comunidade de Itamatatiua a queima da argila é realizada em forno convencional, à lenha, como consequência muitas peças racham durante a queima, por haver variações consideráveis de temperatura durante o longo processo da queima, que pode durar até 48 horas. Já em Porto dos Nascimentos, as Anas queimam a cerâmica em uma fogueira alimentada por cascas de palmeiras. Outra vantagem dessa queima, denominada por elas como "queima no tempo", é que não se precisa juntar muitas peças para realizar a queima, e a produção pode ser rapidamente reposta, em detrimento na queima no forno, em que se precisa juntar muitas peças para justificar o caro e lento processo.

\footnotetext{
4 Entrevista concedida por Ana Amélia em dezembro de 2016 a Raquel Noronha.
} 
Figura 2 - Processo de queima das Anas, denominado por elas como queima "no tempo", diferenciado da queima no forno.

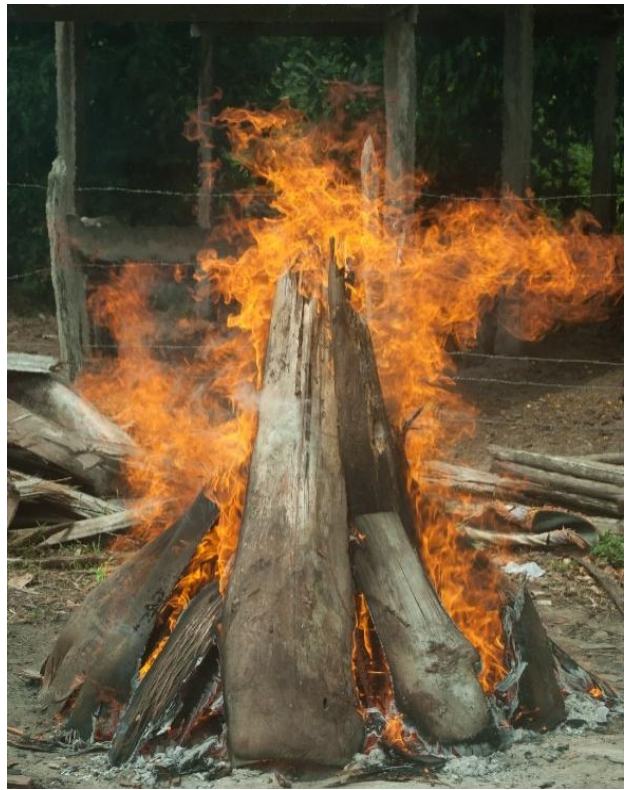

Fonte: Autoras, 2016.

Dentre as prerrogativas de mapear discursos e práticas relacionados a saberes tradicionais, estar em campo é, a priori, a condição sine-qua-non para a construção dos resultados de pesquisa. Somente nesta instância podem ser construídos com a ação entre os sujeitos desta prática. Realizar um projeto desta forma requer uma suspensão no que aprendemos enquanto prática projetual, com a definição de metas e objetivos antes de lançar-se em campo. Assim, estar em campo sem metas específicas pré-definidas ocasiona surpresas e percalços, que fazem parte do próprio percurso metodológico.

Adequações, negociações e desvios de caminhos não são entraves, portanto, à realização do projeto. Contudo é necessário estarmos absolutamente abertos ao que o campo diz, no sentido de potencializar o inusitado e o improviso - vistos por Ingold (2012) como a possibilidade de deixar-se levar pelos fluxos dos materiais e da vida, assim como pelas coisas - denominação que o antropólogo prefere a objeto - enfatizando a capacidade das "coisas" de se relacionarem com o ambiente na qual existe.

Essa abordagem é extremamente valiosa, já que a atividade artesanal lida com tais fluxos de materiais e os improvisos que, muitas vezes, geram soluções criativas e inovadoras, por meio da prática e do processo de tentativa/erro.

Assim foi possível analisar que Zé Dico, mesmo não tendo conhecimento embasado, possui noções de projeto e os utiliza nos seus processos criativos e produtivos, indiretamente, como metodologia. Ele se apresenta como um artesão, que sabe de tudo um pouco, e que aprendeu tudo que sabe com o pai. Possui uma pequena olaria e detém conhecimento sobre o tratamento de barro a partir da experiência que obteve trabalhando em diversas olarias, durante toda a vida com o pai e diz: 
Em todo lugar que eu ando, eu aprendo alguma coisa, já fiz muitos fornos por aí por Alcântara, e esse trabalho de oleria eu aprendi com meu pai. A manjarra eu aprendi quando eu tinha uns dez anos 5 .

Durante a visita em Itamatatiua, conversas sobre a produção da louça e os problemas de rachaduras durante a queima, a questão da limpeza e da mistura do barro com areia foi levantada como possibilidade de solução para o problema. Zé Dico sugeriu que fosse construída uma manjarra, uma espécie de moenda, para amaciar o barro de forma mais ágil, em maior quantidade e qualidade, deixando o barro mais macio e sem pedras ou restos de vegetais, o que pode ocasionar as rachaduras durante a queima.

Considerando a manjarra como um saber associado à produção de alimentos, foi entendido que a sua construção como um processo de transposição de tecnologia social, adaptando-a da produção de alimentos para o gado para a produção artesanal. Adquirimos um tonel solicitado por Zé Dico e ele se encarregou de produzir a pá da moenda, de madeira. Construiu-se a manjarra em dois dias de trabalho e, durante a execução, ele nos indicava seus percursos metodológicos, a partir das experiências anteriores e da prática com os materiais.

A manjarra, como pode ser visto na Figura 3, é uma moenda, cuja pá interna, em forma de hélice, empurra o barro para o fundo do tonel, amaciando-o, quebrando pequenas pedras e impurezas do barro. Deve ser movida por tração animal e, em tese, deveria diminuir o trabalho e a força empregada pelas artesãs na limpeza e amaciamento do barro, etapa da cadeia produtiva de extrema importância (NORONHA, 2011).

Figura 3: Zé Dico e auxiliar movendo o eixo da manjarra.

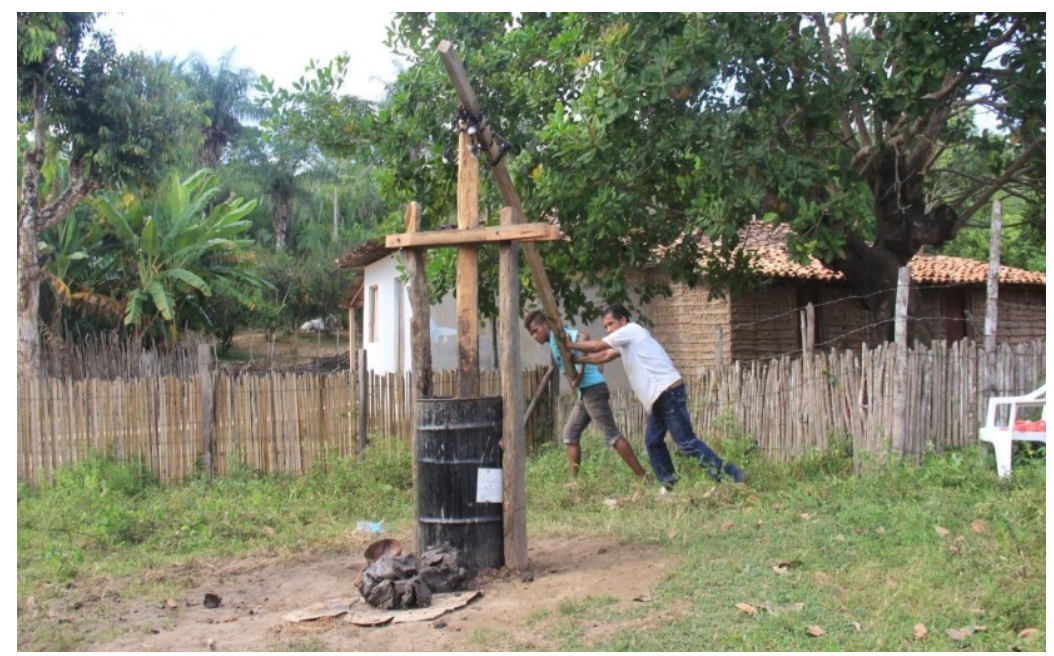

Fonte: Autoras, 2016.

Durante o processo de elaboração do sistema mecânico, Zé Dico ia descrevendo cada ação, que foram cuidadosamente anotadas e desenhadas no diário de campo. Descrevia as "mordeduras" (encaixes) entre as peças, adequando-as ao tamanho do tonel e ao final de cada etapa bem-sucedida dizia: "a senhora tá vendo? Assim que é o projeto". E mostrava como tirava

\footnotetext{
${ }^{5}$ Informações obtidas em conversa informal, durante construção da manjarra, em 16 de junho de 2016, em Itamatatiua.
} 
as medidas: todas foram pensadas de acordo com a proporção do eixo, e ele utilizou de um pedaço de madeira como medida. Esta madeira foi usada como gabarito até o final, quando foi incorporada à própria manjarra. Isso foi observado por Zé Dico de forma estratégica e intencional, já que havia pouca madeira e precisou utilizar o gabarito como peça da manjarra. Ao final do trabalho, perguntou-se a Zé Dico o que ele entendia por projeto, e ele disse:

O que é projeto pra mim? É a pessoa determinar uma obra. Se você... por exemplo, assim: eu tenho um projeto de fazer um forno, então eu vou caçar uma maneira de eu fazer aquele objetivo que eu tô pensando em fazer, então aquilo é um projeto. Eu tenho determinado aqui na minha cabeça que eu vou com as minhas mãos e sei fazer, vou dar por determinado, entendeu? ${ }^{6}$

A ideia de intencionalidade, presente na definição de design, surge nas reflexões do artesão. E continua a discutir a ideia de projeto:

Não é só ter um projeto aqui no caderno, ou fazer um riscadinho com a lapiseira e dizer: "rapaz, e agora, como é que eu vou fazer? Então eu vou falar com um cara lá de São Bento...". Não, eu mesmo vou fazer. Criação, seja um barraco para fazer uma criação, criar qualquer objeto, criar uma horta muito grande, criar um tanque de peixe, tudo eu sei como funciona, porque eu me boto pra aprender... ${ }^{7}$

Zé Dico executou o projeto da manjarra com expertise. Ao longo do processo foi possível observar que tudo, mesmo que aparentemente de forma empírica, estava muito bem calculado. 0 conceito de projeto estava ali expressado claramente na prática.

\section{Cartografias}

Seguindo as pistas cartográficas e as práticas de correspondência, foram criadas táticas para que fosse possível construir o plano comum. A captura da atenção, no processo de construção do comum, foi a primeira chave utilizada. Os resultados parciais das cartografias, já que estas ainda não foram devolvidas aos sujeitos da pesquisa, sendo fruto das reflexões teóricas a partir da prática em campo.

Para se tornarem resultados consolidados será necessário que os artesãos envolvidos neste processo contribuam com suas reflexões para a escrita visual destes mapas.

Aqui, traz-se as representações visuais dos percursos descritos na forma de três cartografias: a do intercâmbio entre as Anas das Louças e artesãs de Itamatatiua (Figura 4), a da construção da manjarra por Zé Dico (Figura 5) e a da cadeia produtiva do taquipé , sobre o uso da casca de madeira, conhecimento compartilhado durante o intercâmbio, em vias de testes e usos experimentais pelas artesãs de Itamatatiua (Figura 6).

\footnotetext{
${ }^{6}$ Entrevista concedida por Zé Dico, em dezembro de 2016, para Raquel Noronha.

7 Idem.
} 
Figura 4 - Cartografia do intercâmbio das Anas e mulheres de Itamatatiua.

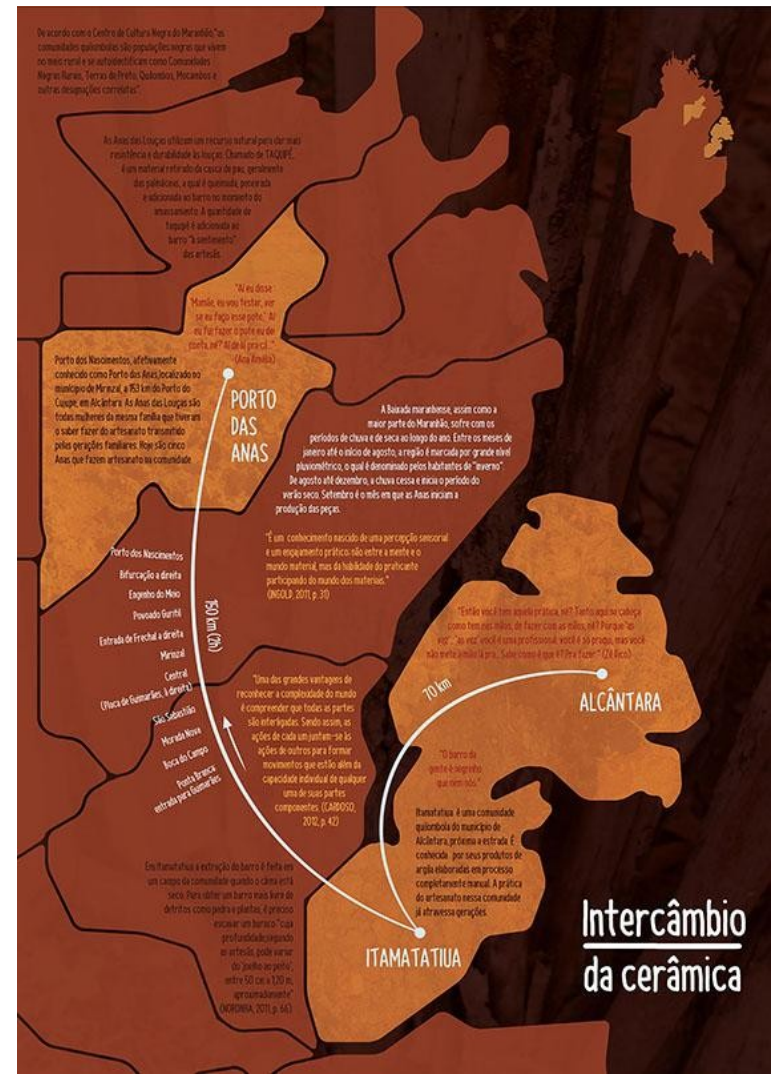

Fonte: Autores, 2017.

Figura 4 - Cartografia sobre a manjarra e Zé Dico

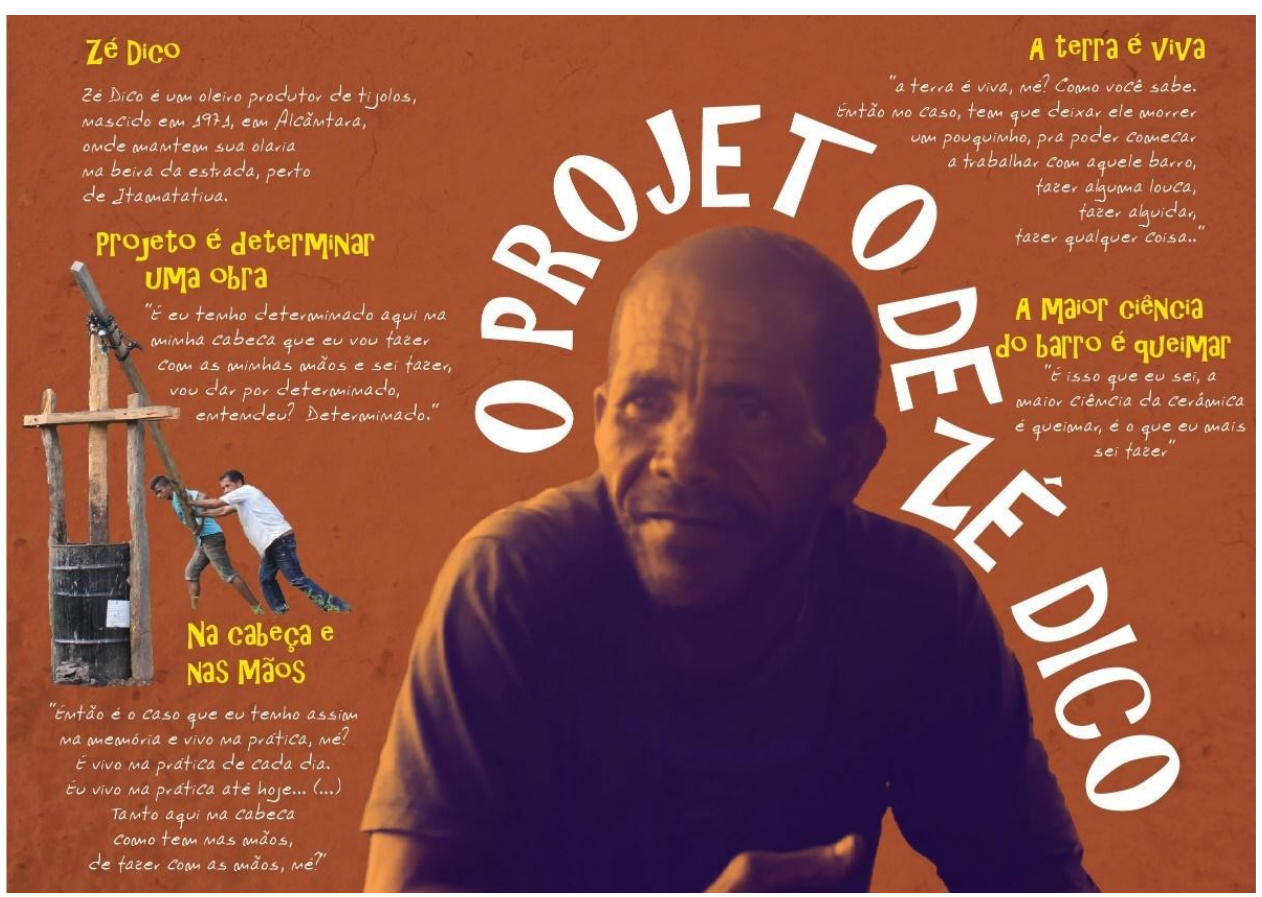

Fonte: Autores, 2017. 
Figura 5 - Cartografia da cadeia produtiva do taquipé.

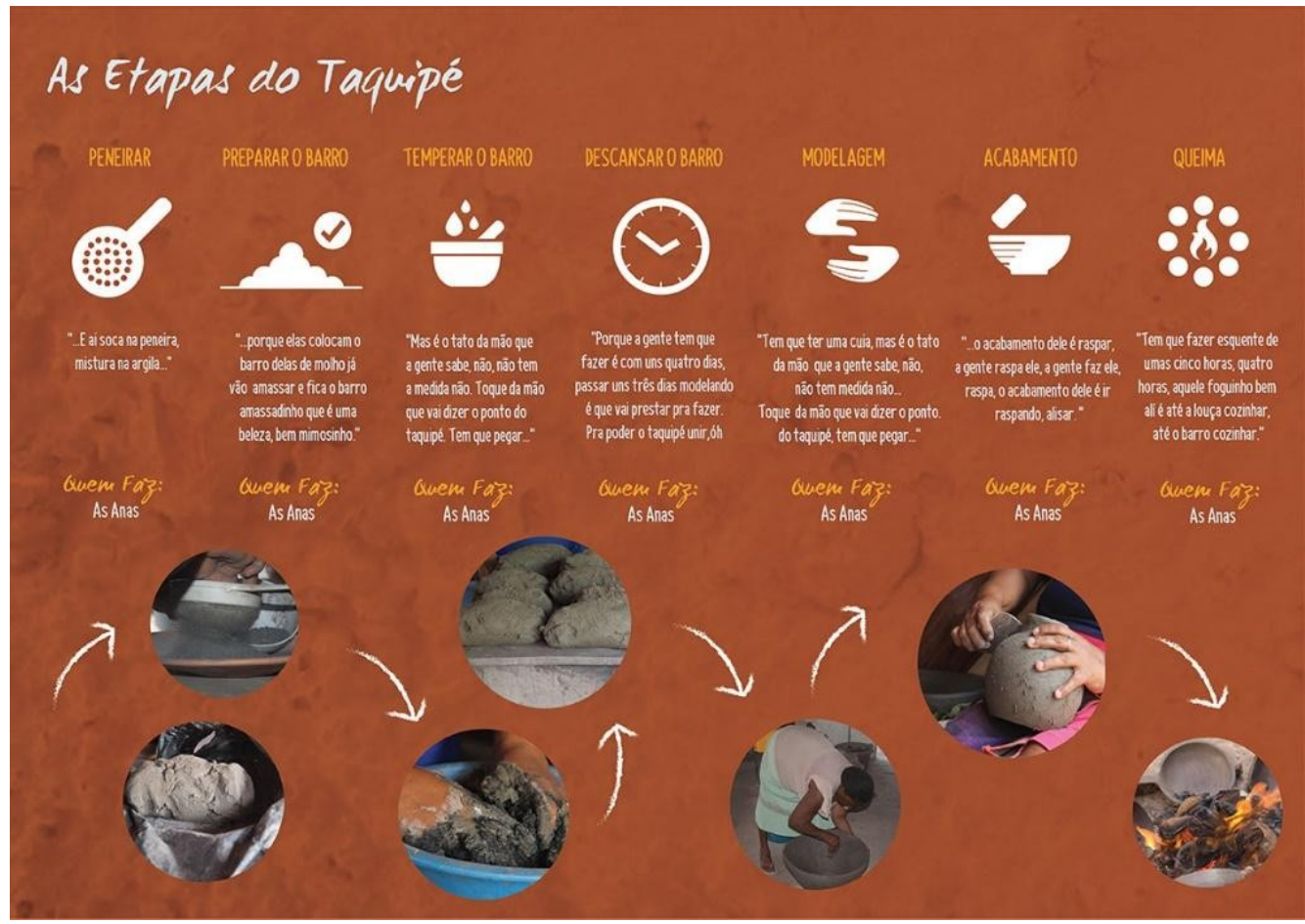

Fonte: Autores, 2017.

\section{Considerações finais}

O processo de aproximação e distanciamento com o próprio conhecimento ajudam a problematizar e ver de forma mais ampla a realidade na qual houve imersão. Os designers, na contemporaneidade, têm papel fundamental, quando se propõem a compartilhar a sua atuação projetual com seus copesquisadores, propiciando ambientes férteis à inovação bottom-up, em potencial.

Dessa forma, ao realizar o convite aos grupos produtivos para fazerem coisas juntos com o grupo visitante as suas cadeias produtivas, está promovendo estes dois movimentos - de afastamento e de aproximação - com o seu próprio saber-fazer. Ao "abrirem" a caixa preta de seus processos produtivos e mostrarem ao outro grupo, reciprocamente, são levados pelas circunstâncias a ordenar seus discursos, a refletir sobre os entraves e as potencialidades de suas produções.

No bojo deste processo, pode-se mapear e analisar os discursos e práticas provenientes destes encontros, na forma de cartografias, apresentadas no item anterior. Mais do que uma forma de representação gráfica, cartografar implica um processo dinâmico, interdisciplinar, que envolve conhecimentos do campo do design, da antropologia, da geografia e da psicologia. Uma busca pela tangibilização compartilhada dos processos colaborativos.

No campo do design, foi possível, com este intercâmbio de saberes, refletir sobre a prática cartográfica e a ideia de projeto, anuindo aos codesigners a possibilidade de terem voz - e imagens - construídas a partir de múltiplos pontos de vista. 


\section{Referências}

CARDOSO, Rafael. Design para um Mundo Complexo, Cosac Naify. São Paulo: 2012. (p. 262);

CLIFFORD, James. A experiência etnográfica: antropologia e literatura no século $X X$. In: GONÇALVES, José Reginaldo. (org.). Editora UFRJ 3a Ed, Rio de Janeiro: 2008. 320p.

FOUCAULT, Michael. Arqueologia do saber, Forense Universitária. Rio de Janeiro: 2010.

INGOLD, Tim. Trazendo as coisas de volta à vida: emaranhados criativos num mundo de materiais. In: Horizontes Antropológicos, Porto Alegre: ano 18, n.37, p. 25-44, jan./jun. 2012.

INGOLD, Tim. Anthropology and/as Education, Routledge. Abingdon: 2018

MANZINI, Ezio. Design, when everybody designs. An introduction to Design for Social Innovation, The MIT Press. Cambridge/London: 2015.

NORONHA, Raquel. Do centro ao meio: um novo lugar para o designer. 2012 (org.). Identidade é valor: as cadeias produtivas do artesanato de Alcântara, EDUFMA.

São Luís: 2011.

O designer e a produção de sentido na construção de iconografias. In: BRASIL, Marcus Ramúsyo (org.) A imagem na idade mídia, EDUFMA. São Luís: 2010. Cap. 2, p.26-47

PASSOS, Eduardo; KASTRUP, Virgínia; ESCÓSSIA, Liliana da. (orgs). Pistas do método da cartografia: Pesquisa-intervenção e produção de subjetividade, Sulina. Porto Alegre: 2015. 207p.

PINK, Sarah. Doing visual ethnography. Images, media and representation in research, Sage. London: 2013.

THACKARA, John. Plano B, o design e as alternativas viáveis em um mundo complexo, Saraiva. São Paulo: 2008. 